\title{
Digital repositories and scientific communication challenge
}

\author{
Radovan Vrana \\ Department of Information and Communication Sciences, \\ Faculty of Humanities and Social Sciences, University of Zagreb \\ Ivana Lučića 3, Zagreb, Croatia \\ rvrana@ffzg.hr
}

\section{Summary}

Digital technology has a great influence on scientific communication and scientific research in general. As a result, science has become more highly collaborative, network-based, and data-intensive seeking for different kinds of support for research as well for other activities that follow research such as rapid publication of research results and dissemination and preservation of research data. Having these issues in mind, the traditional system of scientific communication has also begun search for a new publishing and communication platform. At the beginning of the 1990s digital repositories appeared as a possible solution offering several key advantages over the existing publishing and preservation solutions. At the moment digital repositories of scientific information are closest to the position of new mainstream publishing and communication platform in science as they have become more mature and developed networked information systems; as their number in the world is on the rise and as they have become more and more accepted by the scientific community. While first digital repositories were isolated systems, today they distributed federated and highly integrated applications and services. In combination with the open access initiative, digital repositories of scientific information started to offer many benefits for different groups of users. Furthermore, digital repositories could help smaller countries to become more visible in the global scientific community by offering online open access digital peer reviewed scientific content. Digital repositories should solve problems inherited from the existing paper based system of scientific communication: access to scientific information for different categories of users, storage space, slow publishing, quality and quantity of scientific knowledge, organization of scientific knowledge in transparent way, interoperability of information systems and many other issues scientific publishers, universities and their libraries haven't solved so far. This paper offers an overview of the important characteristics that make digital repositories so important in modern science.

Keywords: Scientific communication, E-science, Scientific publishing, Digital repositories 


\section{Introduction}

Digital technology has a great influence on scientific communication and scientific research in general. Under the influence of digital technology the daily practice of scientists has changed: digital technology has transformed the way in which scientists conduct literature reviews; access research libraries; collect, store and mine research data; publish written research outcomes; communicate with editors and publishers; apply for grants; exchange preprints and reprints; and maintain informal networks with their peers (Genoni, Merick and Wilson 2005). Consequently, science has become more highly collaborative, networkbased, and data-intensive. To conduct and publish their research more effectively, scientists need new and improved platforms for publishing which will support their efforts and facilitate better communication with their colleagues. The system of scientific communication that is still in place is now over 300 years old and it has become clear that it should be changed to meet the information needs of modern scientists. The widespread availability of scientific digital content on the internet is already creating opportunities for new forms of research and scholarship that are qualitatively different from the traditional way of using academic publications and research data (Arms and Larsen 2007). Use of digital technology and changes in the ways in which scientists conduct research, collect and analyze data, and communicate their findings to colleagues and scholarly communities (Kafel 2012) has sped up the development of one new information system - the digital repository with aim for the digital repository to become publishing and communication platform. At the moment digital repositories of scientific information are closest to the position of a new mainstream publishing and communication platform in science as their number in the world is on the rise and as they become more widely accepted by scientists and their universities. This paper will discuss the characteristics of digital repositories of scientific information in the prism of change in the scientific communication paradigm.

\section{Scientific communication paradigm change}

Like many other areas of human endeavor, scientific communication has been facing challenges introduced partially but significantly by the rapid development of the internet in the 1990s. Before the 1990s, scientific communication was based on printed journals (and other printed publications), there was a substantial lag in refereeing articles and publishing journals, and the distribution system for scientific papers was clumsy and slow, resulting in difficulty for researchers trying to keep up with new developments in their field (Cullen and Chawner 2010). Additionally, scholars and researchers in many countries suffered from a lack of access to the current literature in their field because of high journal subscription prices as well as per article or conference paper prices (Shearer 2003). By being in some cases unable to pay for access to scientific journals, universities lost control over their published scientific output. During 
the 1990s scientific communication was undergoing a revolution comparable to the one occasioned by the invention of printing: new ways of creating, reviewing and presenting scientific work were introduced as well as a new information system - thorough and systematic in its distribution, potentially global in scale, almost instantaneous in speed and interactive (Harnad 1990). This new information system is called a digital repository i.e. a digital archive of the scientific output of the members of a scientific community. Digital repositories were designed with the idea of solving the problem of the organization of large quantities of scientific knowledge which exceed the ability of individual scientists to identify and utilize all relevant information needed for research (Lawrence 2001). Digital repositories were also created to become a new publishing platform for academic intuitions enabling them to regain complete control over their scientific output and to make this output more visible.

Another significant initiative that appeared in the 1990s and that helped digital repositories to become more accepted globally by scientists and visible was open access. "The open access literature is digital, online, free of charge, and free of most copyright and licensing restrictions" (Sawant 2013: 16). Open access "means that a reader of a scientific publication can read it over the internet, print it out and even further distribute it for non-commercial purposes without any payments or restrictions" (Björk 2004). The European Commission points out that definitions of open access "(...) describe "access" in the context of open access as including not only basic elements such as the right to read, download and print, but also the right to copy, distribute, search, link, crawl, and mine" (Guidelines on Open Access to Scientific Publications and Research Data in Horizon 2020 2013: 2). "Open access to a repository adds easy availability of content that may come from various sources to the advantages of no cost or unlimited access to information (Calderón y Enar Ruiz 2013: 194).

Open access offers many benefits for different groups of users. Researchers can benefit from open access in the following ways: their articles are freely accessible online; the authors hold copyright for their work and grant anyone the right to reproduce and disseminate the article, provided that it is correctly cited; a copy of the full text of each open access article is permanently archived in an digital repository separate from the journal; authors are assured that their work is disseminated to the widest possible audience, the widespread availability of articles will enhance literature searching; the results of publicly funded research will be accessible to all interested readers and not just those with access to a library with a subscription; a country's economy will not influence its scientists' ability to access articles (Chiao and Schmidt 2004). Scientists and institutions they work in will attract more funding as their scientific outputs will be more visible and accessible in open access digital repositories. As a result, digital repositories hold the potential to increase the use and application of research so the people who decide on funding the development of digital repositories will 
decide more easily which repository project to support (Zuccala, Thelwall, Oppenheim and Dhiensa, 2006).

The general public can also benefit from open access: greater access to research outputs without the often prohibitive costs associated with traditional publishing; no requirement for passwords or other forms of authentication; greater access to academic research findings for those researchers, academic and professional, who work outside academia; ensuring that those who actually provide the money for publicly-funded research (i.e. tax-payers) have access to the outputs they have funded (Suber 2007). Open access has revolutionized the scientific communication paradigm by opening a new chapter in the development of the global system of scientific communication that will enable scientists and readers to publish and access scientific knowledge more easily than ever.

While open access is accepted more widely than ever before (judging from the constantly increasing number of open access digital repositories registered in the Registry of Open Access Repositories (http://roar.eprints.org/) and in The Directory of Open Access Repositories - OpenDOAR (http://www.opendoar. org/), it is still not universally accepted and because of that and because of unwillingness of major world publishers to move their businesses completely to the digital environment for publishing adapted for more cheaper access to the scientific output, the paradigm shift in scientific communication and scientific publishing hasn't occurred yet.

\section{Digital repositories: responding to the communication challenge of modern science}

Open access and digital repositories are closely connected as open access literature can usually be delivered in two ways (Zainab 2010): open access digital repositories and open access journals. Digital repositories are more interesting as they aggregate scientific journals (and other types of publications) and offer access to the content of a variety of publications in digital format.

Digital repositories are digital archives of the intellectual product created by the faculty, research staff, and students of an institution and are accessible to end users both within and outside the institution, with few if any barriers to access (Johnson 2002). A digital repository can be owned and managed by an individual, a small group, an institution or commercial organization, a consortium of organizations or a government entity (Branin 2003). That makes it applicable in many different situations where reliable scientific information resources are needed. Digital repositories offer scientists a way to manage and disseminate the digital materials created by the individual academic institution and by the scientific community members. Essentially they represent an organizational commitment to the stewardship of these digital materials, including long-term preservation where appropriate, as well as their organization and access or distribution (Lynch 2003). Digital repositories are archival, stewardship and dissemination systems for content that have a fairly heavy policy component in 
terms of who can deposit, what metadata is required for deposit, acceptable formats and the implications of format choices for institutional preservation guarantees (McLean and Lynch 2003). Digital repositories are also information systems and service models designed to collect, organize, store, share, and preserve an institution's digital information or knowledge assets worthy of such investment (Branin 2003).

Digital repositories aim to replace the traditional systems for publishing and preservation of scientific information. Because of that, their functions can be compared to those of a traditional printed journal to see whether this idea is possible. Prosser (2005) chose traditional functions of journals: registration the author wishes to ensure that she is acknowledged as the person who carried out a specific piece of research and made a specific discovery; certification through the process of peer review it is determined that the author's claims are reasonable; awareness - the research is communicated to the author's peer group; archiving - the research is retained for posterity. Then he compared journals with digital repositories which showed that digital repositories mirror at least three functions of traditional journals: registration - by depositing in the repository the researcher would make claim to their discovery; awareness - by constructing the repository to open access initiative standards the institution would ensure that the researcher's work would be found by search engines and available to their peers. New alerting services could be developed that would inform readers of new papers deposited in any repository that matched their research interests (in the same way that journal table of contents can be received); archiving - the institution would be responsible for maintaining the long term archive of all the work produced by members of that institution. This would place the focus of archiving back onto the library community where it has rested for centuries, rather than on the publisher community where it has migrated following the transfer from print to online. In many cases the research library will be best placed to maintain over many decades an archive of its own research. This comparison proves that digital repositories are ready for taking over role of main publishing medium in science.

In addition to the enumerated three functions of the traditional journal, Prosser suggested that there are many benefits to institutional digital repositories (Prosser 2005: 1) For the individual: they provide a central archive of the researcher's work; by being free and open they increase the dissemination and impact of the individual's research; they act as a full CV for the researcher 2.) For the institution: they increase the institution's visibility and prestige by bringing together the full range and extent of that institution's research interests; they act as an advertisement for the institution to funding sources, potential new researchers and students, etc. 3.) For society: they provide access to the world's research; they ensure long-term preservation of institutes' academic output; they can accommodate increased volumes of research output (no page limits, can accept large data-sets, 'null-results', etc.). Visibility of scientific output of a 
country is very important as it helps scientists and institutions they work in to attract funds for new research. By visibility we mean how avidly published work is received by the academic or scientific community (Miguel, ChinchillaRodríguez and de Moya-Anegón 2011: 1130).

Digital repositories are of extreme importance in e-science for care of published scientific works and research data. E-science is most commonly referring to scientific activities supported by high bandwidth computer-mediated telecommunications networks, and particularly to encompass the variety of such digital information-processing applications that are expected to be enabled by the grid i.e. the general purpose network technology which will serve to facilitate new, computationally intensive forms of scientific inquiry (David 2003). E-science offers better support to collaborative science i.e. the ability to have broader interactions through the sharing of data, experimental approaches and both intermediate and final results in systems that will maintain a history of the data, processes, outcomes and conversations among scientists (Wright, Sumner, Moore and Koch 2007). For e-science to be successful, new communication and publishing infrastructure is needed. This new infrastructure must facilitate broader interactions through the sharing of data, experimental approaches and both intermediate and final results in systems that will maintain a history of the data, processes, outcomes and conversations among scientists (Wright, Sumner, Moore and Koch 2007). Almost all these are already possible in digital repositories or will be possible in the near future.

While rather well developed, digital repositories are far from being perfect and without problems. Some of these include: low awareness of their existence among scientists and in scientific institutions; scientists being unmotivated to deposit the results of their work in digital repositories; long term financing; lack of technical support; lack of long term development policies; lack of clear policies or guidelines for the identification of material to be stored; copyright issues that prevent different publications being stored or made openly accessible; issues around the mandatory peer review of digital content as well as to its authenticity and long term preservation bot of published works and research data. Calderón $(2013,199)$ analyzed digital repositories at the top 50 European universities and suggested aspects of their development and operation which put them in the leading position. These aspects are: the language of the repository, the diversity of the content, the size of the institution or its funding. In another study Koulouris, Kyriaki-Manessi, Giannakopoulos and Zervos (2013: 770) emphasized another problem related to the success of digital repositories in academic community: faculty members' attitude towards use of digital repositories. They were not familiar with open access benefits, were suspicious of open access policies and were hesitant because publishing rights and publishing policies are not clear. As a result, scientists are reluctant to publish results of their work in digital repositories, but, instead they still use journals as the primary channel for publishing and communication. Obviously, every university should 
promote digital repositories to its members and have very clear written policies about publishing and/or archiving scientific works in digital repositories. Furthermore, scientists should be given incentives to publish and store results of their research and other forms of work in digital repositories. So far, there are not very many cases in which scientists' academic advancement is related to their active use of digital repositories. It is also expected that digital repositories will act as data sharing platforms (e.g. for the re-use of research data and learning objects) (Poynder 2006: 15). The main point in accepting digital repositories in the daily scientific routine is receiving the political, organizational, financial, technical and human resources support from the university (or other scientific institution) in which the digital repository exists. Unfortunately, this is not the case in many universities, so digital repositories are developed under the care of university libraries which are often understaffed, unequipped and not properly funded to maintain digital repositories in the long run. The global economic crisis might advance the development of digital repositories as universities have tighter budgets for scientific journal subscriptions so part of these funds can be re-directed to the development and management of digital repositories. In such cases digital repositories might prove to be a very feasible solution to the publishing, dissemination and preservation problems in scientific communities of different sizes (Business Models, Costs and ROI, 2009).

\section{Open access journals and digital repositories in Croatia}

Open access is present in Croatia in form of open access journals, books and open access digital repositories. Journals in Croatia benefited from the open access as it introduced "a great advantage and enhanced transparency of the whole research and publishing process and helped in promotion science in Croatia globally" (Stojanovski 2015: 20). The portal "Hrčak" ("Hamster" in English)(http://hrcak.srce.hr/) currently offers access to 388 journals with 127197 full text articles which is the largest number of available full text articles in Croatia in one place. These articles and other open access resources are becoming more extensively used in research and teaching in higher education institutions in Croatia as a replacement for fee based information resources (Vrana 2014). The current list of the Directory of Open Access Repositories at http://www.opendoar.org/countrylist.php?cContinent=Europe includes only seven digital repositories from Croatia. While this number is very small in comparison to some other European countries, these digital repositories have an important role as promoters of open access in the Croatian academic community and serve as role models for future digital repositories in Croatia. Academic libraries which are most closely connected to digital repositories still do not have the adequate support in form of financial resources, hardware, software, written policies, education and training and political support at their universities (Vrana 2010; Vrana 2013). "Libraries at the Croatian universities are facing many challenges and are making efforts to improve the conditions in areas such as de- 
velopment of information infrastructure, education and training of library staff, securing financial resources, etc. which are all important for the development and management of digital repositories thus creating the bridge towards e-science" (Vrana 2013: 150). As a result of these sometimes unfavorable conditions, the number of digital repositories in Croatia hasn't increased in years. Nevertheless, the existing digital repositories are important for scientific communities in scientifically peripheral counties as they help in making scientific output of such countries more visible (Stojanovski, Petrak and Macan 2009; Markulin and Šember 2014).

\section{Conclusion}

The system of scientific communication has been on the verge of change for some time. In spite of numerous announcements of paradigm change, the existing communication paradigm hasn't changed very much. It has been improved by digital technology to facilitate easier and faster access to published scientific knowledge but it didn't change scientific publishing radically. It has become clear that this change will not happen instantly; instead it will happen over time in several different phases in which different parts of the scientific communication system will be improved and in which these improvements will be carefully implemented. Small countries with limited visibility in the scientific community could benefit greatly from the latest changes in scientific communication oriented towards the development and use of digital repositories of scientific information. Digital repositories of scientific information might be included in one of the most important phases of change, because they could improve directly publishing and offer use of open access materials and ensure their long term preservation. The proof of their advancement can be found in the history of their development. In the last 20 years, digital repositories have come a long way from isolated systems towards distributed, federated and highly integrated applications and services (Jones 2007: 155). Today, digital repositories still have the same goals to fulfill i.e. to "(...) centralize, preserve, and make accessible an institution's intellectual capital, at the same time they will form part of a global system of distributed, interoperable repositories that provides the foundation for a new disaggregated model of scholarly publishing" (Johnson 2002). Development of digital repositories is still burdened by problems such as long term funding, lack of infrastructure and support from the academic community (Vrana, 2014) which slows down their development. In spite of that, their number is constantly growing. Generally speaking, digital repositories already offer the outputs of the institution or community to the world; they maximize the visibility of outputs; they showcase and sell the institution to interested constituencies; they collect and curate digital outputs; they manage and measure research and teaching activities; they provide and promote a workspace for workin-progress, and for collaborative or large-scale projects; they facilitate and further the development and sharing of digital teaching materials and aids; and 
they support and sustain student endeavors (Swan 2008; Kelly and Eells, 2015). These are all reasons why digital repositories could be accepted even more widely by many universities around the world and especially in smaller countries where they might become crucial for the development of the national scientific communication infrastructure and improve the visibility of these countries in the global scientific community.

\section{References}

Arms, W.; Larsen R. The Future of Scholarly Communication: Building the Infrastructure for Cyberscholarship. 2007. http://www.sis.pitt.edu/ repwkshop/SISNSFReport2.pdf (15.12.2014.)

Björk, B. C. Open access to scientific publications - an analysis of the barriers to change. // Information research. 9(2004), 2 http://www.informationr.net/ir/9-2/paper170.html (15.12. 2014.)

Branin, J. Institutional repositories. 2003. https://kb.osu.edu/dspace/bitstream/1811/441/1/inst_ repos.pdf (15.12.2014.)

Business Models, Costs and ROI (2009). http://www.openoasis.org/index.php?option=com content\&view $=$ article \&id $=166 \&$ Itemid $=357$ (9.7.2015.)

Calderón, Aurora Ruiz. The Participation and Web Visibility of University Digital Repositories in the European Context. // Comunicar. 20(2013), 40; 193-200.

Chiao, P.J.; Schmidt, C. Open Access gains attention in scholar communication. // Molecular Cancer. 23(2004), 3; 1-2

David, P. A.; Spence, M. Towards institutional infrastructures for e-Science: the scope of the challenge. Oxford: The University of Oxford, 2003

Directory of Open Access Repositories at http://www.opendoar.org (9.7.2015.)

Genoni, P.; Merrick, H.; Willson, M. The use of the internet to activate latent ties in scholarly communities. // First Monday. 10(2005), 12 http://firstmonday.org/issues/issue10_12/gen oni/index.html (15.12.2014.)

Guidelines on Open Access to Scientific Publications and Research Data in Horizon 2020, http://ec.europa.eu/research/participants/data/ref/h2020/grants_manual/hi/oa_pilot/h2020-hioa-pilot-guide_en.pdf (15.12.2014.)

Hrčak portal. http://hrcak.srce.hr/ (9.7.2015.)

Johnson, R. K. Institutional repositories: partnering with faculty to enhance scholarly communication. // D-Lib Magazine. 8(2002), 11 http://www.dlib.org/dlib/november02/johnson/ (15.12. 2014.)

Jones, R.. Giving birth to next generation repositories. // International Journal of Information Management. 27(2007); 154-158

Kelly, J.; Eells, L. Global scholarship The role of subject repositories in advancing research from the developing world. // College \& Research Libraries News. 76(2015), 5; 265-268

Koulouris, A.; Kyriaki-Manessi, D.; Giannakopouloa, G. Institutional repository policies: best practices for encouraging self-archiving. // Procedia - Social and Behavioral Sciences. 73(2013); 769-776

Lawrence, S. Free online availability substantially increases a paper's impact. // Nature. (2001), $411 ; 521$

Lynch, C. Institutional repositories: essential infrastructure for scholarship in the digital age. // ARL Bimonthly Report. (2003), 226, http://www.arl.org/resources/pubs/br/br226/br226ir. $\operatorname{shtml}(15.12 .2014$.)

Markulin, H.; Šember, M. University of Zagreb Medical School Repository: promoting institutional visibility. // Croatian medical journal, 55(2014); 89-92. 
McLean, N.; Lynch, C. Interoperability between Information and Learning Environments: Bridging the Gaps. 2003 http://www.imsglobal.org/DLims_white_paper_publicdraft_1.pdf (15.12.2014.)

Miguel, S.; Chinchilla-Rodríguez, Z.; de Moya-Anegón, F. Open Access and Scopus: A New Approach to Scientific Visibility From the Standpoint of Access. // Journal of the American society for information science and technology, 62(2011), 6; 1130-1145.

Poynder, R.. Clear blue water. 2006 http://www.openscholarship.org/upload/docs/application/ pdf/2009-01/poynder___irs.pdf (15.12.2014.)

Prosser, D. C. The Next Information Revolution - How Open Access will Transform Scholarly Communications. // International Yearbook of Library and Information Management 20042005: Scholarly Publishing in an Electronic Era. London : Facet Publishing, 2005, 99-117

Sawant, S. Open access resources useful in LIS education. // Library Hi Tech News. 30(2013), 7; 16-20

Shearer, K. Institutional Repositories: Towards the Identification of Critical Success Factors. // Canadian journal of information and library science. 27(2003), 3; 89-108

Stojanovski, J. Do Croatian open access journals support ethical research? Content analysis of instructions to authors. // Biochemia Medica, 25(2015), 1; 12-21.

Stojanovski, J.; Petrak, J.; Macan, B. The Croatian national open access journal platform. (2009) https://bib.irb.hr/datoteka/430563.stojanovski_et_al.pdf (9.7.2015.)

Suber, P. Open Access in 2007. // The Journal of Electronic Publishing. 11(2008), 1 http://dx.doi. org $/ 10.3998 / 3336451.0011 .110$ (15.12.2014.)

Swan, A. The business of digital repositories in A DRIVER's Guide to European Repositories. Amsterdam: Amsterdan university press, 2008, 15-47

Vrana, R. Access to digital information resources as a support to academic achievement. // Central European Conference on Information and Intelligent Systems - CECIIS 2014. Varaždin : Faculty of Organization and Informatics, University of Zagreb, 2014, 144-151.

Vrana, R. Digital repositories at the Croatian universities: providing support for the enhancement of research and teaching. // MIPRO 2010 33rd International convention on information and communication technology, electronics, and microelectronics, Rijeka : Croatian society for information and communication technology, electronics and microelecronics, 2010, 141-146.

Vrana, Radovan. Digitalni repozitoriji i stvaranje informacijske infrastrukture // Četvrti festival hrvatskih digitalizacijskih projekata / Petrušić, Renata ; Marasović, Nela ; Hraste, Matilda ; Zajec, Jasenka (ur.). Zagreb : Nacionalna i sveučilišna knjižnica u Zagrebu, 2014. 41-42

Vrana, R. Digital repositories of scientific information at the Croatian universities: Developing the bridge towards e-science. // Information Technology Interfaces (ITI), Proceedings of the ITI 2013 35th International Conference. Zagreb : University Computing Centre ; University of Zagreb, 2013. 145-150

Zainab, A. N. Open Access repositories and journals for visibility: Implications for Malaysian libraries. // Malaysian Journal of Library \& Information Science. 15(2010), 3; 97-119

Zuccala, A; Thelwall, M.; Oppenheim, C. Dhiensa, R. Digital Repository Management Practices, User Needs and Potential Users: An Integrated Analysis. http://cybermetrics.wlv.ac.uk/ DigitalRepositories/FinalReport.pdf, 2006. (9.7.2015.)

Wright, M.; Sumner, T.; Moore, R.; Koch T. Connecting digital libraries to eScience: the future of scientic scholarship. // International Journal on Digital Libraries. 7(2007), 1; 1-4 